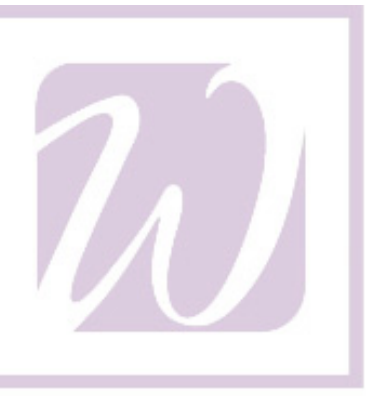

UW-WHITEWATER

\title{
Volatility and Persistence of Simulated DSGE Real Exchange Rates
}

\author{
By \\ Yamin Ahmad, UW-Whitewater \\ Ming Chien Lo, St. Cloud State University \\ Olena Mykhaylova, University of Richmond \\ Working Paper 11 - 01
}

University of Wisconsin - Whitewater

Department of Economics

$4^{\text {th }}$ Floor Hyland Hall

800 W. Main Street

Whitewater, WI 53190

Tel: (262) $472-1361$ 


\title{
Volatility and Persistence of Simulated DSGE Real Exchange Rates
}

\author{
Yamin Ahmad* \\ Ming Chien $\mathrm{Lo}^{\dagger}$ \\ University of Wisconsin - Whitewater \\ St. Cloud State University \\ Olena Mykhaylova $a^{\ddagger}$ \\ University of Richmond
}

\begin{abstract}
We investigate the time series properties of both filtered and unfiltered real exchange rate series produced by DSGE models that feature local currency pricing, home bias, nontraded goods, and incomplete markets. Detrended series produced by several specifications approach the empirically observed volatility, although none of the models generate enough persistence. Conversely, several models produce unfiltered series that possess the same degree of persistence as the data, but none can match its volatility.
\end{abstract}

JEL Classification: F41 F47 C15 C32

Keywords: Volatility, Persistence, Real exchange rate dynamics, DSGE modeling

* Corresponding author. Department of Economics, 800 W Main Street, Whitewater, WI 53190. Email: ahmady@uww.edu. Homepage: http://facstaff.uww.edu/ahmady/. Tel: (262) 4725576

${ }^{\dagger}$ Department of Economics, Stewart Hall 380, St. Cloud State University, 720 Fourth Avenue South, St. Cloud, MN 56301. Email: mclo@stcloudstate.edu

$\ddagger$ Department of Economics, Robins School of Business, 28 Westhampton Way, University of Richmond, VA 23173. Email: omykhayl@richmond.edu 


\section{Introduction}

Research findings related to the Purchasing Power Parity (PPP) puzzle hinge critically on the method used to separate data into the trend and cyclical components. We evaluate the ability of dynamic stochastic general equilibrium (DSGE) models in replicating the observed volatility and persistence of real exchange rates (RER) by considering the time series properties of both filtered and unfiltered simulated data. The former approach - in the spirit of Chari, Kehoe and McGrattan (2002), henceforth CKM — is quite common in the business cycle literature and corresponds to extracting the long-run trend from the data and analyzing the remaining deviations. The latter methodology, widely used in time series studies, examines deviations from PPP and treats all fluctuations in the data as cyclical, implicitly assuming that PPP holds in the long run. Our contribution lies in presenting a comprehensive summary of the several commonly used extensions of a two-country DSGE framework in regards to resolving the PPP puzzle by extending the analysis beyond business cycle frequencies.

\section{Model}

Since the model we use is well documented in the literature, we relegate its description and equilibrium equations to an online appendix, available for download from the authors' websites, and focus on the contributions of its four widely used features to the RER dynamics.

The benchmark model consists of two countries, each populated by infinitely lived households of measure one that derive utility from consumption and leisure, possess monopolistic power over their wages, and have access to a complete contingent claims market. Each country has measure one of monopolistically competitive firms that use country-specific labor and capital to produce a continuum of tradable goods varieties, which are available for consumption by both home and foreign agents. Both wages and prices, set by the households and the firms, respectively, are sticky à la Calvo. Each country's independent monetary policy can be described by a variant of the Taylor Rule, in which the short-term nominal interest rate responds (with inertia) to deviations of inflation and output from their targets. Finally, government purchases follow an autoregressive process, and both governments balance their budgets every period. The choice of shocks has non-trivial consequences for the behavior of exchange rates. Monetary policy, which requires the presence of nominal rigidities to affect real variables, must itself be quite persistent to generate the observed RER half-lives. On the other hand, real shocks, such as government spending and 
technology, generate the hump-shaped response of exchange rates seen in the data (Steinsson, 2008); we include all three disturbances in our model.

The benchmark specification, where PPP holds at all times, contains nominal rigidities (which may generate deviations from the law of one price, LOP) as the only source of RER movement. However, this specification produces virtually no RER dynamics. Instead, we consider - first one at a time, and then in several combinations - its four widely used extensions that break the PPP relationship: home bias, local currency pricing, nontraded goods, and incomplete markets.

Home bias in consumption allows for a different composition of home and foreign consumption baskets, which decouples movements in the two countries' aggregate price levels, thus breaking the absolute PPP relationship. Hence, the RER responds to terms of trade fluctuations.

Empirical evidence points to a rather low degree of pass-through from exchange rates to import prices. We therefore follow CKM and Corsetti, Dedola and Leduc (2008)-hereafter CDL-among others, and add international price discrimination by firms, which may optimally choose to charge different prices at home and abroad. Now, the RER responds to deviations from LOP that arise due to pricing-to-market.

Nontraded goods allow for an alternative way to lower the degree of pass-through from exchange rates to inflation. To this end, we add a continuum of firms, which, similar to the producers of the tradables above, hire capital and labor from local households to produce one of the varieties of nontradable goods. Public and private consumption is now composed of both traded and nontraded goods. Due to the Balassa-Samuelson effect, relative technological growth between traded and nontraded sectors generates RER movements.

We also consider an incomplete financial markets extension of the model, where we continue to assume that all consumers can perfectly share risks within a country; a risk-free bond issued by the foreign country can be traded internationally. Home households can buy the bond at a price that depends on their country's aggregate position in the international asset market. This specification breaks the uncovered interest parity relationship between real interest rates and exchange rates and also decouples the movements of the latter from the dynamics of relative consumptions.

We follow CKM in parameterizing our model; nontraded sector is calibrated as in CDL (the detailed description of the parameters is available in the online appendix). Each time period in the model corresponds to one quarter. Most of the parameters are quite common and noncontroversial in 
international DSGE literature; two of them deserve special mention. We assume a high level of consumer risk aversion, which CKM show is critical for generating the right amount of RER volatility. We also calibrate the monetary shock processes to match the observed volatility and cross-correlation of the two GDPs. Therefore, a very close match between the simulated and actual second moments of the RER would not be surprising, since the calibration has been chosen to favor such an outcome; on the other hand, a gap between the model and the data would indicate that the PPP puzzle remains present even in the most recent class of models. Robustness checks on both of these parameterizations do not alter our main results, but produce a worse fit vis-à-vis the data.

The model is solved using first-order perturbation methods (with second-order computations performed as a robustness check); computer code is written in Dynare.

\section{Results}

\subsection{Empirical Properties of RER}

We assume that the data (both simulated and actual) may be succinctly captured by a univariate autoregressive process of the form

$$
q_{t}=\lambda_{1} q_{t-1}+\ldots+\lambda_{p} q_{t-p}+\varepsilon_{t}
$$

where $\varepsilon_{t}$ is white noise. The series is stationary if the sum of the autoregressive coefficients, $\left|\sum_{i=1}^{p} \lambda_{i}\right|$, is less than 1. Re-writing (1) into an augmented Dickey-Fuller regression form allows us to estimate a measure of the RER persistence:

$$
q_{t}=\Lambda q_{t-1}+\varphi_{1} \Delta q_{t-1}+\ldots+\varphi_{p-1} \Delta q_{t-p+1}+\varepsilon_{t}
$$

Consequently, the RER dynamics are governed by the key parameters $\left\{\lambda_{1}, \ldots, \lambda_{p}\right\}$, since $\varphi_{j}=$ $-\left(\lambda_{j+1}+\ldots+\lambda_{p}\right)$ for $j=1, \ldots, p-1$ and $\Lambda \equiv \sum_{j=1}^{p} \lambda_{j}$. The parameter $\Lambda$ represents our measure of persistence of the underlying data generating process. ${ }^{1}$ Below we also report its median unbiased estimate and the 5 and 95 percentiles of the distributions using the Andrews and Chen (1994) method, which is robust to the presence of a unit root in the series.

\footnotetext{
${ }^{1}$ If the underlying RER process is autoregressive of order one, its persistence is captured by the estimated AR(1) coefficient. Persistence of higher-order processes is less intuitive and more difficult to measure, especially if the true order of autoregression is not known. We follow the suggestion of Dias and Marquez (2010), which incorporates the information from all the estimated AR coefficients to measure RER persistence.
} 
When fitting (2) to both the actual and simulated RER series, we allow the data to select the order of autoregression using the Schwarz-Bayes Criterion (SBC), and then compute the Ljung-Box Q statistics to ensure that our model has adequate fit. If the null of no serial correlation in the residuals is rejected, we increase $p$, re-estimate (1) and repeat the test until we are unable to reject the null.

The properties of the actual data for several G7 countries in our sample are summarized in Table 1. ${ }^{2}$ For the 1975Q2-2009Q4 period, we are unable to reject the null hypothesis of a unit root in the RER series for all of the countries. Given the low power of unit root tests, this result is unsurprising. Several papers have found that once longer spanning data is utilized, the behavior of the real exchange rate appears to be stationary (e.g., Lothian and Taylor, 1996). Moreover, we find that $\Lambda$, the sum of the autoregressive coefficients, is less than one in absolute value for all countries.

\begin{tabular}{|l|c|c|c|c|c|c|}
\hline & Canada & France & Germany & Italy & Japan & UK \\
\hline \hline Autocorrelation & 0.96 & 0.93 & 0.93 & 0.94 & 0.95 & 0.92 \\
ADF Test & -1.81 & -1.92 & -1.73 & -2.20 & -2.20 & -2.27 \\
PP Test & -1.75 & -1.99 & -1.89 & -1.82 & -2.13 & -2.52 \\
$\lambda_{1}$ & 1.16 & 0.94 & 1.02 & 1.08 & 1.21 & 1.10 \\
$\Lambda$ & 0.96 & 0.94 & 0.95 & 0.94 & 0.94 & 0.91 \\
\hline \hline & & & & & & \\
$\mathrm{p}$ & 2 & 1 & 2 & 4 & 2 & 2 \\
$\sigma_{R E R} \%$ & 11.84 & 16.21 & 17.13 & 17.33 & 19.25 & 14.07 \\
LJB Test & 3.73 & 1.00 & 0.26 & 1.33 & 3.22 & 2.71 \\
$\Lambda_{M U E}$ & 0.99 & 0.98 & 0.99 & 0.96 & 0.97 & 0.94 \\
{$[5 \% \quad 95 \%]$} & {$[0.931 .02]$} & {$[0.911 .02]$} & {$[0.911 .02]$} & {$[0.910 .99]$} & {$[0.911 .01]$} & {$[0.861 .01]$} \\
\hline
\end{tabular}

Table 1: Time series properties of RER for different countries between 1975Q2-2009Q4.

Notes: The ADF and PP tests report the values of the augmented Dickey-Fuller and Phillips Perron test statistics, respectively. Volatility $\left(\sigma_{R E R}\right)$ is expressed in percent. MUE represents the median unbiased estimate of $\Lambda$. Figures in square brackets represents the 5 and 95 percentiles for the median unbiased estimate of the persistence parameter, computed using Stock's (1991) method.

\subsection{Filtered Data Analysis}

The second and third columns of Table 2 present the business cycle properties of the simulated HP-filtered data. In addition to examining the four extensions outlined above, we also study several of their combinations. Thus, row marked CKM refers to the specification that includes both local currency pricing (LCP) and home bias (we dub this version CKM since Chari, Kehoe and McGrattan, 2002 used it in their analysis). The following two rows add nontraded goods

\footnotetext{
${ }^{2}$ The bilateral RER series used in our paper come from the IFS dataset and are computed as $Q_{t} \equiv \frac{S_{t} P_{t}^{*}}{P_{t}}$, where $S_{t}$ is expressed as U.S. dollars per national currency (series ..AG.ZF), and $P_{t}$ measures consumer prices for all items (series 64...ZF).
} 
(CKM_NT) and (separately) incomplete markets (CKM_IM) to the CKM model.

The presence of LCP, which limits the pass-through of exchange rate movements to national prices, produces much more volatile RER compared to other basic model extensions, although it still falls short of the volatility in the data. The CKM_NT version produces the closest match of RER volatility, albeit still falling short by over $10 \%$. Turning to persistence, we find that nontraded goods is the likeliest specification to match the empirical autocorrelation of the RER, although it slightly undershoots it.

Overall, we conclude that the DSGE framework (outfitted with certain structural features like LCP or nontraded goods) is capable of replicating the observed RER volatility and persistence, although more work needs to be done to bring moments of the models in closer correspondence with the data. Since these results are quite in line with the findings in the literature (for example, CKM and CDL), we now extend our analysis to the unfiltered simulated series, analogous to the data used in the time series literature examining RER dynamics.

\subsection{Persistence and Volatility of Unfiltered Data}

For each version of the model, we generate 1000 trials (each 5000 observations long) of the (log) real exchange rate and then examine the properties of the simulated data in order to infer the underlying dynamics embedded within the series.

Our choices of the autoregression order are presented in column 4 of Table 2. Panel A of Table 2 indicates that the median value of selected $p$ belongs to the $\{1,2\}$ set in all the trials; thus, our findings informally suggest that the theoretical models match the data along this particular dimension.

Persistence and volatility of the simulated series have been difficult to replicate in theoretical models. The average volatility of the actual log RER series across our sample of countries (Table 1) is 16 percent. However, as shown in panel A of Table 2, none of the models approach that degree of volatility; the CKM_NT version against most closely resembles the data, although the distribution of volatilities generated across the thousand trials still falls short of the empirical findings. ${ }^{3}$

\footnotetext{
${ }^{3}$ Although we report the mean volatility in the table, the median volatility is approximately the same, at least to three decimal places.
} 


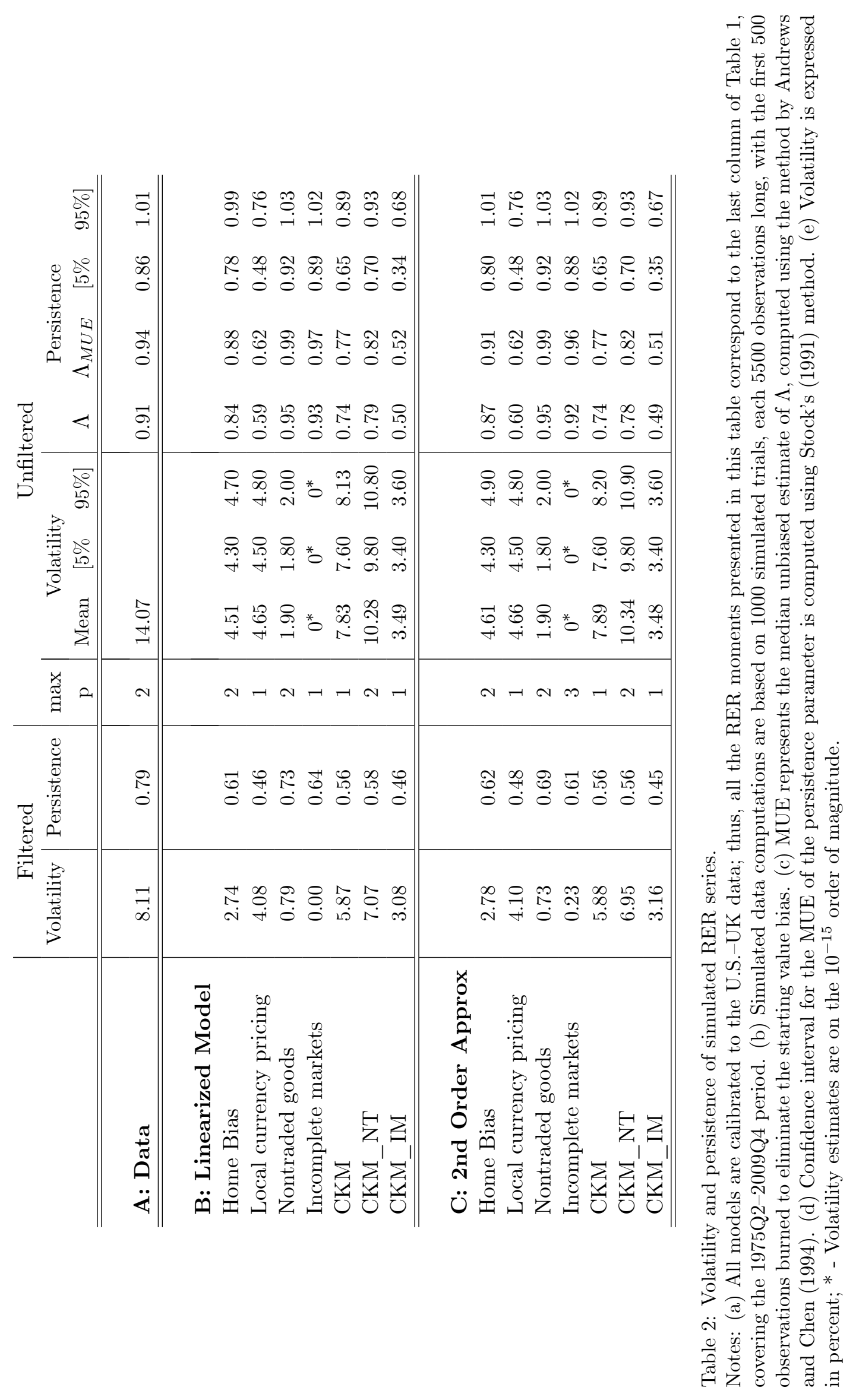


This is somewhat surprising, given that the nontraded goods specification generates very little volatility by itself. Clearly, the interaction of extensions contained in CKM_NT (pricing-to-market, home bias, and nontraded goods) yields a more volatile RER than any individual specification.

Regarding persistence, we find that the nontraded goods and (separately) incomplete markets extensions are able to generate sufficiently persistent RERs, comparable to those found in the data, and that the home bias specification falls somewhat short of the empirical estimates. As earlier, the CKM specification does not generate sufficiently persistent RER. Only when nontraded goods are added to the mix, do we obtain persistence in the neighborhood of what is seen in the data. Interestingly, the CKM_IM version does not perform nearly as well as either of its basic components. Once again, we conclude that the interactions of individual building blocks of our models produce patterns in RER dynamics that are quite distinct from those in the building blocks themselves.

\subsection{Second-Order Approximation}

As a robustness check, we also examine the RER series simulated using a second order approximation to the model equations, which may manifest higher levels of volatility and persistence given the theoretical complexity and the presence of structural nonlinearity embedded in the DSGE models. Panel $\mathrm{C}$ of Table 2 reports these findings.

We observe an increase in volatility of filtered RER series for the incomplete markets and CKM_IM versions of the models vis-à-vis the first order solution. Unfiltered RER volatility is slightly higher in the home bias, CKM, and CKM_NT specifications of the model. Overall, the results here show that there are few gains in volatility to be obtained by using second order approximations.

Persistence of the filtered series remains virtually unchanged when they are simulated to the second order of approximation. Examining unfiltered persistence, we find a small increase - of approximately $3 \%$ - for the home bias version. In the remaining cases, persistence is unchanged or marginally lower. Thus, we conclude that the greatest gains from second order approximation (in terms of absolute levels) for unfiltered persistence are obtained in the home bias case.

\section{Conclusion}

This paper examines the extent to which RER series generated using medium-scale DSGE models exhibit persistence and volatility observed in the data. We analyze both filtered and unfiltered RER properties; this approach allows us to examine all frequencies of the data without imposing 
restrictions (specific filters) on its behavior and without losing information contained in its longrun trend. We find that the solutions put forth in response to the CKM critique do a good job in matching RER volatility when both data and simulated series are HP-filtered; however, only the nontraded goods extension comes close to matching RER persistence. On the other hand, unfiltered series produced by several of the models (specifically, nontraded goods and incomplete markets) possess similar degree of persistence as the actual data, which is typically used in time series estimation. At the same time, none of the specifications produce the observed unfiltered RER volatility. Of course, it is not surprising that persistence of the filtered data is lower than that of the unfiltered series: by controlling for the trend, we are removing some of its long-run determinants. These results are robust to the choice of solution method (first or second order approximation), although persistence and volatility increase slightly with the order of approximation. Overall, it appears that more work is warranted before theoretical DSGE models can adequately account for the PPP puzzle.

\section{Acknowledgements}

We would like to thank Neil Ericsson, Jun Ma, and Pedro Gete for helpful comments on an earlier version of the paper. We are also grateful to session participants at the Georgetown Center for Economic Research (GCER) 2011 conference, the SNDE 2011 conference and the anonymous referee for suggestions that helped improve the paper. Any errors remaining in the paper, are of course, our own.

\section{References}

Andrews, D., Chen, H.-Y., 1994. Approximately median-unbiased estimation of autoregressive models. Journal of Business and Economic Statistics 12, 187-204.

Chari, V.V., Kehoe, P., McGrattan, E., 2002. Can sticky price models generate volatile and persistent real exchange rates? Review of Economic Studies 69, 533-563.

Corsetti, G., Dedola, L., Leduc, S., 2008. High exchange-rate volatility and low pass-through. Journal of Monetary Economics 55, 1113-1128.

Dias, D., Marques, C.R., 2010. Using mean reversion as a measure of persistence. Economic Modelling 27, 262-273.

Lothian, J.R., Taylor, M., 1996. Real exchange rate behavior: the recent float from the perspective of the past two centuries. Journal of Political Economy 104, 488-509.

Steinsson, J., 2008. The dynamic behavior of the real exchange rate in sticky price models. Amer- 
ican Economic Review 98, 519-533.

Stock, J., 1991. Confidence intervals for the largest autoregressive root in the U.S. macroeconomics time series. Journal of Monetary Economics 28, 435-459. 